\title{
Visual evoked potential monitoring of optic nerve function during surgery
}

\author{
G F A Harding, J D P Bland, V H Smith
}

\begin{abstract}
A study was made with intra-operative flash-visual evoked potentials (VEP) monitored using a fibre-optic/contact lens photo stimulator in 57 patients undergoing intra-orbital surgical procedures with potential risk to the optic nerve. The VEPs recorded under enflurane and nitrous oxide anaesthesia did not differ significantly in latency or amplitude from the pre-operative recordings. Transient abolition of the VEP was seen under many circumstances and did not correlate with the outcome of surgery, but absence of a previously normal VEP for more than four minutes during surgical manipulation within the orbit did show a correlation with post operative impairment of vision. The technique provides early warning to the surgeon of threats to the integrity of the optic nerve.
\end{abstract}

All neurosurgical and intra-orbital surgery in the region of the anterior optic pathway carries some risk to vision. The visual evoked potential (VEP) offers a way of monitoring the function of the visual pathway during such surgery and perhaps a means by which a proportion of visual morbidity may be avoided. Attempts have been made for some years to introduce this technique, mainly in neurosurgical procedures, but a review of the literature regarding its usefulness and even feasibility reveals considerable variation in the perceived value of this form of monitoring. Reports involving small numbers of neurosurgical patients have generally been optimistic. ${ }^{1-4}$ Reports of a larger series of patients, both neurosurgical and ophthalmological, fall into two groups.

Several authors have found intraDepartment of Vision Sciences, University of Aston, Birmingham G F A Harding

Queen Elizabeth Hospital, Birmingham J D P Bland

Birmingham and Midland Eye Hospital, Birmingham VH Smith

Correspondence to: Professor Harding, Department of Vision, Sciences, Aston University, Aston Triangle, Birmingha B4 7ET, United Kingdom.

Received 11 August 1989 and in revised form

and in revised form

Accepted 22 February 1990 the correlations seen between surgical events, intra-operative VEPs and clinical outcome in the most recent 25 patients. Finally we discuss the possible application of this technique to neurosurgical practice in situations such as those reported by other authors. ${ }^{2-411} 12$

\section{Materials and method}

Between 1984 and 1988, 57 patients undergoing intra-orbital surgery at the Birmingham and Midland Eye Hospital have had flashVEPs recorded during the procedure using the Aston Stimulator. Twenty eight operations were bilateral and two patients were operated on twice thus the total number of eyes monitored during surgery was 87 . The pathology involved is shown in table 1. Ages ranged from 15 to 76 years. Twenty four patients were male and 33 female.

Pre-operative assessment was initially limited to conventional assessment of visual acuity and other measurements as indicated by the underlying pathology (table 2 ). All but nine patients had pre-operative flash and pattern reversal VEPs recorded. Responses were recorded in theatre as described by Harding et $a l .{ }^{13} \mathrm{~A}$ flash stimulus was generated by a normal photostimulator discharge tube enclosed in a stimulator with a reflective inner surface. A $5 \mathrm{~mm}$ fibre-optic cable carried this stimulus from a socket located on the axis of the cylinder to a prism mounted on a $24 \mathrm{~mm}$ haptic trans-curve contact lens (Medelec Ltd). The lens and fibre-optic cable were sterilised and placed on the eye at the beginning of surgery, being held in place by two stitches passed through the eyelids on either side of the prism. This apparatus delivers a stimulus of comparable intensity to a conventional stroboscope as measured by the amplitude of the ERG. ${ }^{4}$ Responses were collected from a single channel montage (active-Oz, reference-Fz) using a Nicolet CA1000 averager, amplifier gain of 100 microvolts $/ \mathrm{cm}$ and a bandpass of $1-30 \mathrm{~Hz}$. The pupils were dilated immediately before surgery to minimise the effects of small displacements of the contact lens on the VEP. Averaging runs of 32 stimuli at a repetition rate of $1.6 \mathrm{~Hz}$ were adequate to generate clear responses. Initially only one stimulator was available and this was transferred to the second eye for monitoring the bilateral procedures but after patient 23 a second stimulator allowed simultaneous monitoring of both eyes. Details of long term outcome up to a maximum of four years were obtained from the case-notes. After initial experimentation anaesthetic procedure 
Table 1 Operations carried out with VEP monitoring 1984-1988

\begin{tabular}{|c|c|c|c|c|c|c|}
\hline & \multicolumn{3}{|c|}{$\begin{array}{l}\text { Orbital decompression for } \\
\text { dysthyroid eye disease }\end{array}$} & \multirow{2}{*}{$\begin{array}{l}\text { Orbital } \\
\text { tumours }\end{array}$} & \multirow{2}{*}{$\begin{array}{l}\text { Traumalforeign } \\
\text { body in orbit }\end{array}$} & \multirow[b]{2}{*}{ Total } \\
\hline & Medial & Lateral & Both & & & \\
\hline $\begin{array}{l}\text { Unilateral } \\
\text { Bilateral }\end{array}$ & $\begin{array}{r}7 \\
25\end{array}$ & $\begin{array}{l}0 \\
1\end{array}$ & $\begin{array}{l}\mathbf{0} \\
\mathbf{2}\end{array}$ & 19 & 5 & $\begin{array}{l}31 \\
28 \\
59\end{array}$ \\
\hline
\end{tabular}

became standardised, induction being with diprivan or etomidate and maintenance with enflurane $(1 \%)$ and nitrous oxide.

\section{Results}

1) Feasibility of monitoring

In only three cases was it impossible to obtain adequate VEPs at the beginning of surgery. In these cases monitoring was abandoned. We were therefore able to apply this technique to $95 \%$ of patients including some with initially very poor visual acuity (worse than $6 / 60$ ). In two cases there was such gross swelling around the orbit that suturing of the contact lens in place proved impossible. Nevertheless,

Figure 1 VEPs recorded during removal of an $R$ orbital plasmacytoma via a medial approach in an 88 year old woman.

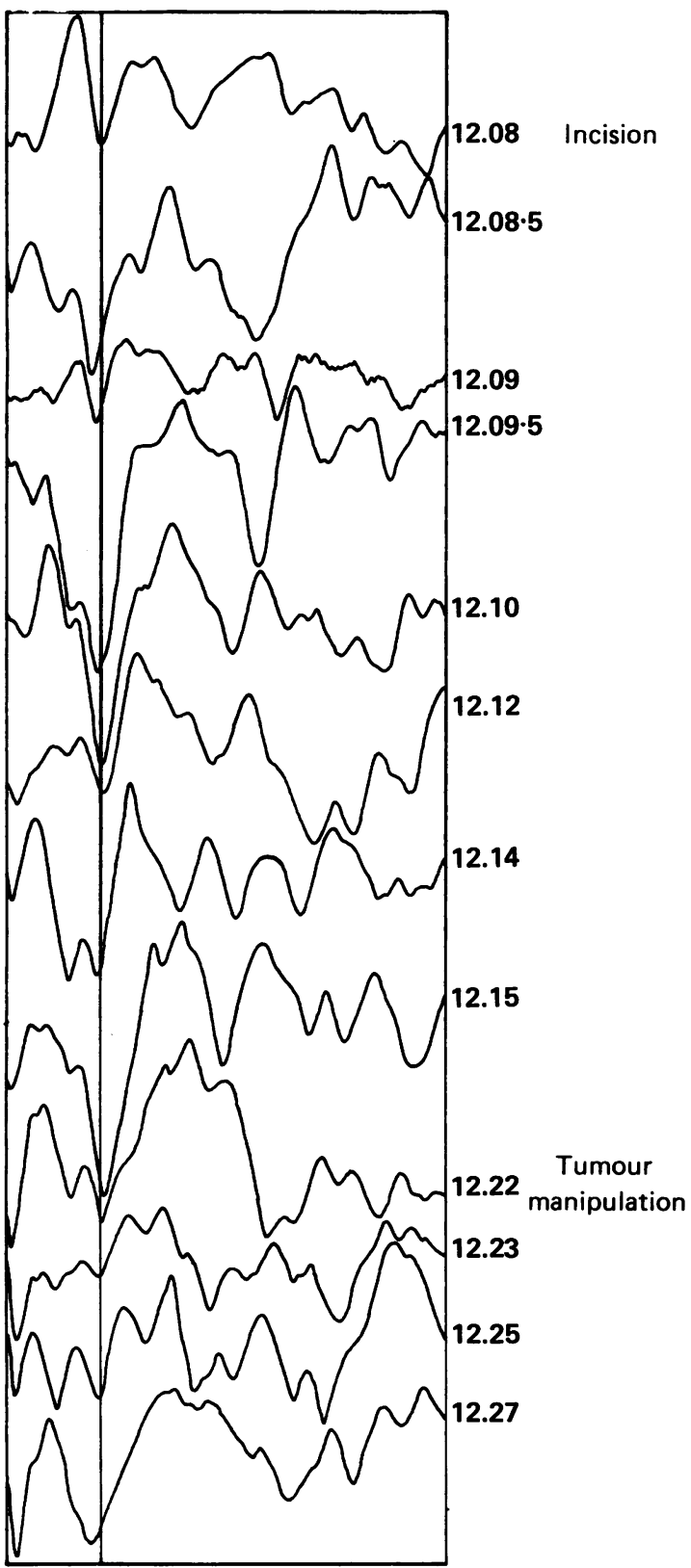

even in these cases, with intermittent manual application of the contact lens, adequate intraoperative potentials were obtained.

\section{2) Quality of intra-operatively recorded} potentials

We have compared the P2 latency and N2-P2 amplitude in the pre-operative records with the same measurements made in the early stages of operations before the surgical incision (table 3). Statistical analysis revealed no significant differences (paired $t$ test, $\mathrm{t}>$ $0 \cdot 1$ ) though the variability of the latency under anaesthesia was increased. Examples of traces recorded during uneventful surgery are shown in fig 1 and 2.

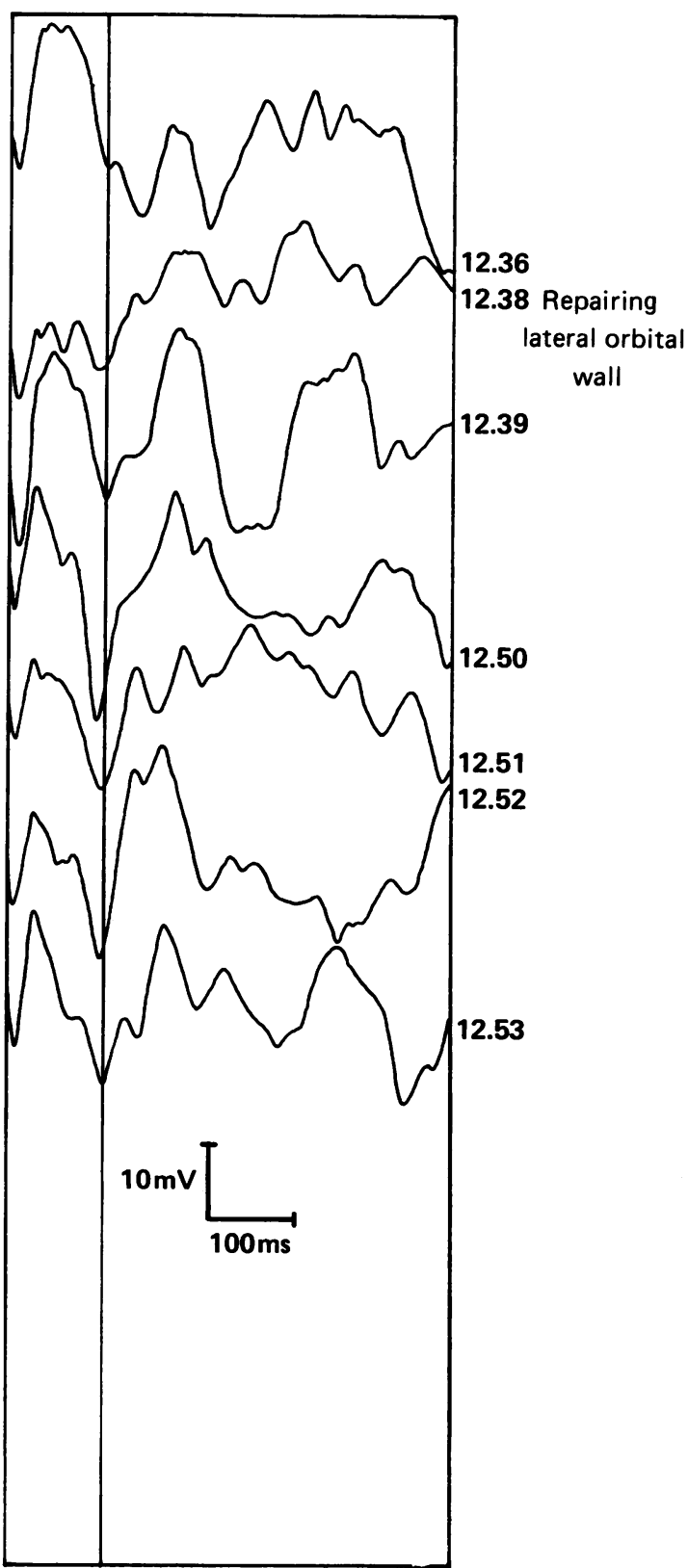


Table 2 Corrected visual acuity of patients before surgery

\begin{tabular}{lc}
\hline Acuity & Number of eyes \\
\hline $6 / 6$ or better & 20 \\
less than $6 / 6$ to $6 / 9$ & 34 \\
less than $6 / 9$ to $6 / 18$ & 16 \\
less than $6 / 18$ to $6 / 36$ & 9 \\
less than $6 / 36$ to $6 / 60$ & 3 \\
Counting fingers or hand movements & 4 \\
Unknown & 1 \\
Total & 87 \\
\hline
\end{tabular}

3) Correlations with surgical and anaesthetic events

In this retrospective review of material it is not possible to make statistically significant correlations between the VEP changes and surgical events but certain observed phenomena appear sufficiently convincing to us to justify further systematic investigation. We noted from an early stage in our studies, marked, apparently spontaneous, variations in the P2 latency during surgery which obviously made it unreliable as a marker of surgical threat. On looking at the amplitude of the flash-

Figure 2 VEPs recorded during bimedial orbital decompression for dysthyroid exophthalmos in a 41 year old woman.

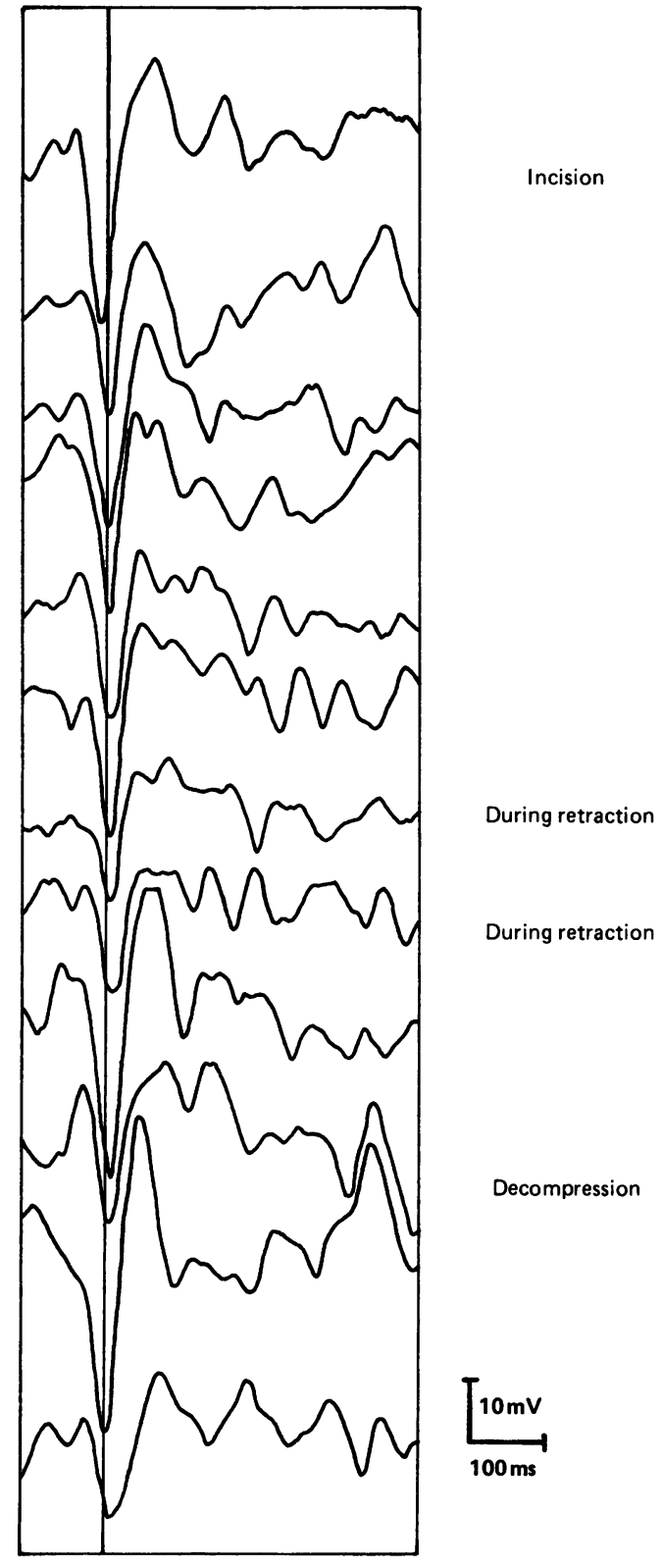

VEP complex, however, it became apparent that although this too exhibited considerable trial to trial variation, a potential could almost always be seen in the absence of any change in anaesthetic or surgical insult. In contrast once surgical operations in the orbit started there were frequently periods during which neither repeated standard averaging runs (32 sweeps) nor single prolonged runs revealed any convincing VEP at all. Careful observation by the surgeon and anaesthetist, combined with repeated short run averaging shows that most of these periods coincided with one or more of the following events:

a) Hypotension (systolic BP $<50 \mathrm{~mm} \mathrm{Hg}$ ), seen only on one occasion

b) Change of anaesthetic agent to halothane or isoflurane (three patients)

c) Displacement of the contact lens stimulator (three patients)

d) Disturbance of the optic nerve due either to direct pressure or to lateral or rotational displacement of the globe.

In the first three conditions the VEP became visible again within three minutes of the correction of the presumed cause. In the case of retraction of the eyeball, if the surgeon was warned of the absence of the VEP and the lateral retraction was reduced, the VEP amplitude rapidly returned and a good outcome was achieved. Example traces showing a degree of spontaneous latency and amplitude variation and brief total abolition of responses are shown in fig 3. However where the VEP had been absent for more than four minutes before retraction was relaxed these cases often showed more delayed recovery of the VEP. In a few cases no further responses were seen up to the end of surgery when monitoring was discontinued. In other cases there appeared to be some overall decrease in VEP amplitude. We have also seen abrupt abolition of responses corresponding to deliberate section of the optic nerve during the removal of an optic nerve glioma (fig 4). In addition we have found that no responses can be obtained for approximately 45 minutes after the induction of anaesthesia with thiopentone (one patient).

Since it appeared that the ability to compare the fellow eye with the eye undergoing surgery would allow separation of the effects of systemic factors such as anaesthesia from those of surgical intervention, we have used this as our standard procedure in 48 operations. Even where bilateral operations were performed the eye not undergoing surgery at any one time was used as a control. Where effects were seen in the VEP from both eyes these could therefore be assumed to be systemic and not directly concerned with the surgical intervention whereas abolition of the VEP from the eye undergoing surgery whilst the VEP from the fellow eye remained clearly present was a clear indication of surgical threat.

4) Correlation with the outcome of surgery Analysis was limited to the most recent group of patients to exclude those patients monitored during the development of the technique and anaesthetic protocol. Complete abolition of the 
Figure 3 VEPs recorded during excision of mass (chronic dacryoadenitis) from the right orbit via a lateral approach in a 67 year old woman.
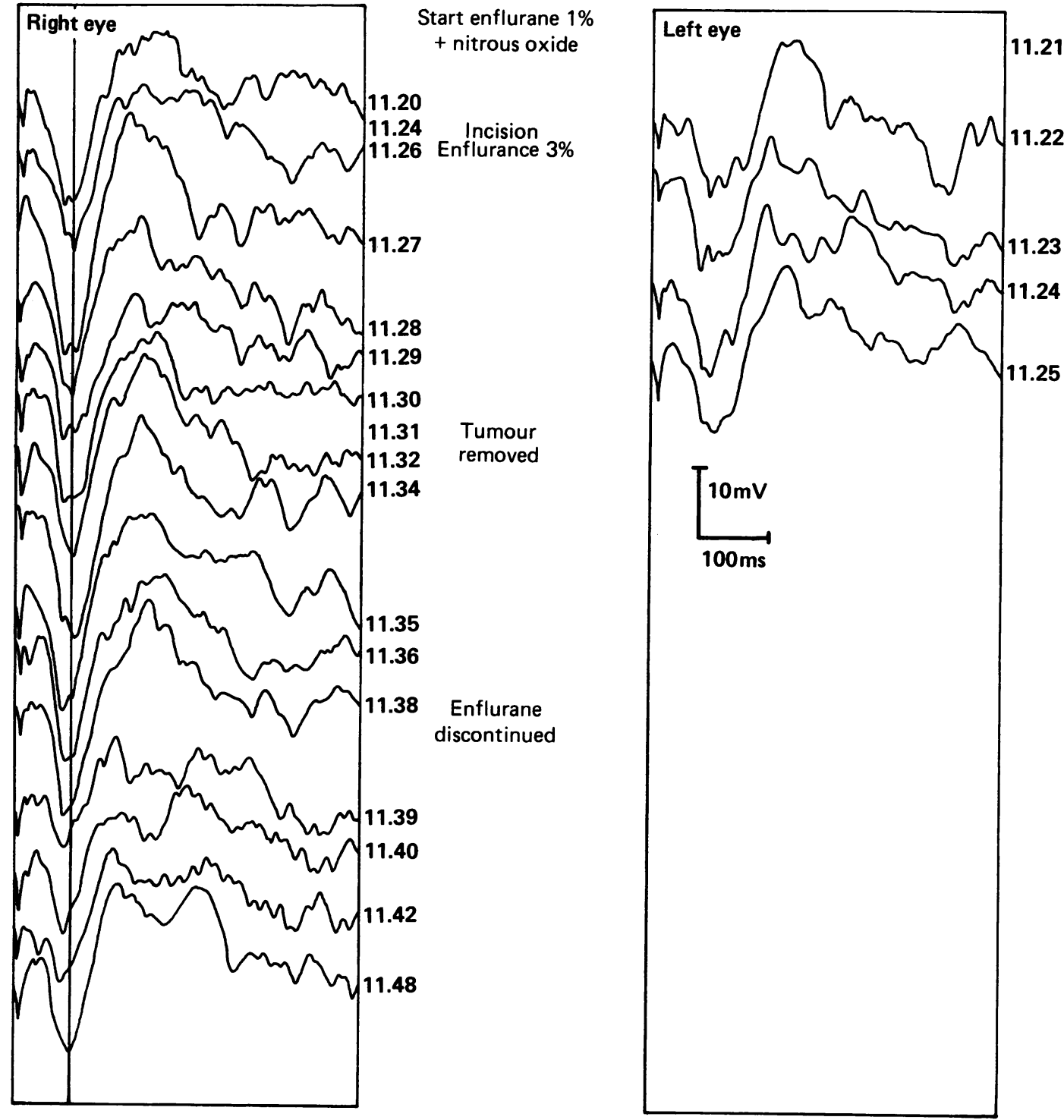

VEP (obtained using the LED stimulator) during surgery is, as reported by other authors ${ }^{9}$ a relatively common occurrence. Prolonged abolition of the VEP recorded by our technique is a much rarer event. The correlation of this observation with the outcome of surgery in terms of visual acuity is shown in table 4 .

\section{Case report}

A 54 year old man with a seven year history of thyrotoxicosis presented with severe bilateral exophthalmos and deteriorating visual acuity. Initial treatment with steroids was of only partial benefit and a surgical decompressive procedure was deemed essential. Immediately before surgery the corrected visual acuity was $6 / 9$ in the right eye and 6/36 in the left eye and the VEPs were normal. A bilateral medial orbital decompression was carried out by an approach through the medial canthus. VEPs were monitored throughout. During surgery on the left eye the VEP was absent for a period of 10 minutes while retraction was applied to the eyeball. The course of the visual acuity post operatively is shown in fig 5 indicating the deterioration in vision in the left eye.

\section{Discussion}

\section{1) Our result}

Intra-operative flash-VEPs are clearly a great deal more variable, both between individuals and within one individual over a short time, than flash-VEPs recorded in the evoked potential laboratory. The flash-VEP is already recogideal for a diagnostic test even in ideal conditions. We believe that the increased variability seen in our intra-operative recordings stems from the interaction of multiple influences on the visual pathway including variations in the depth of anaesthesia, ventilatory state, local blood flow and surgical manipulation combined with the difficulties of delivering a consistent stimulus and recording in an electrically noisy environment. All of these individual factors have been documented as having an effect upon the flash-VEP. ${ }^{15}$

Although several previous investigators have concluded that this increased variability precludes the use of this method during surgery because of an unacceptable false positive rate this conclusion appears to have been based on a conventional, and laboratory derived, definition of what constitutes an abnormal flashnised to exhibit more natural variability than is 
Figure 4 VEPs recorded during excision of a right optic nerve glioma in a 15 year old girl.
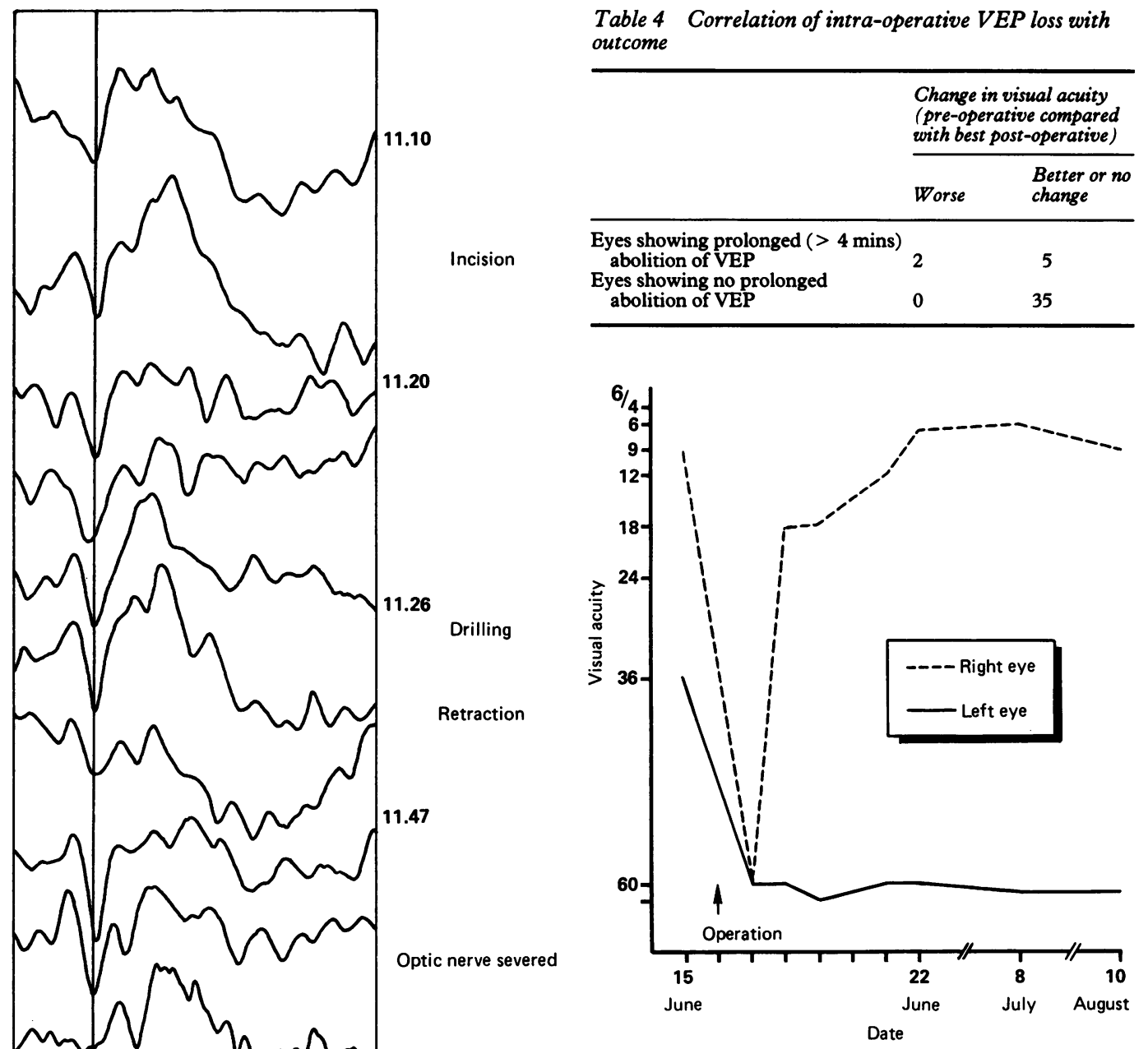

Figure 5 Changes in visual acuity after bimedial orbital decompression for dysthyroid eye disease in a 54 year old man.

\section{2) Further developments}

Our experience with the Aston stimulator suggests that it generates a more robust VEP during surgery than previously reported stimulators based on LEDs possibly by delivering a brighter stimulus ${ }^{14}$ and we therefore believe that further, controlled and prospective studies of the value of this form of monitoring are now required.

The pressing need is for studies in neurosurgical practice in which the risk to vision is greater and the indications for surgery more common. We would suggest that absence of the VEP for four minutes should prompt a search for a remediable cause of damage to the optic pathway by the surgeon. The application of this rule at the Birmingham and Midland Eye Hospital during recent operations may account for the remaining substantial incidence of false

Table 3 Comparison of pre-operative and early operative VEPS

\begin{tabular}{|c|c|c|c|c|c|c|}
\hline & & \multirow{2}{*}{$\begin{array}{l}\text { No of } \\
\text { eyes }\end{array}$} & \multicolumn{2}{|c|}{ Pre-operative } & \multicolumn{2}{|c|}{ During early surgery } \\
\hline & & & Mean & $(S D)$ & Mean & $(S D)$ \\
\hline Latency (ms) & $\begin{array}{l}\mathbf{R} \\
\mathbf{L} \\
\text { All }\end{array}$ & $\begin{array}{l}26 \\
26 \\
52\end{array}$ & $\begin{array}{l}127.4 \\
126 \cdot 1 \\
126.7\end{array}$ & $\begin{array}{c}(13 \cdot 5) \\
(11 \cdot 6) \\
(12 \cdot 5)\end{array}$ & $\begin{array}{l}119 \cdot 2 \\
130 \cdot 5 \\
124 \cdot 9\end{array}$ & $\begin{array}{c}(22 \cdot 0) \\
(24 \cdot 7) \\
(23 \cdot 8)\end{array}$ \\
\hline Amplitude $(\mu \mathrm{V})$ & $\begin{array}{l}\mathbf{R} \\
\mathbf{L} \\
\text { All }\end{array}$ & $\begin{array}{l}27 \\
27 \\
54\end{array}$ & $\begin{array}{l}11.0 \\
10.3 \\
10.6\end{array}$ & $\begin{array}{l}(4 \cdot 3) \\
(7 \cdot 5) \\
(5 \cdot 6)\end{array}$ & $\begin{array}{l}12.6 \\
13.7 \\
13.2\end{array}$ & $\begin{array}{l}(5 \cdot 6) \\
(6 \cdot 1) \\
(5 \cdot 8)\end{array}$ \\
\hline
\end{tabular}


positive (five out of seven recent "positives" by this criterion).

Extending the period of VEP suppression which we are prepared to tolerate during surgery might reduce this figure further but at the risk of introducing a number of false negatives which are clinically more important. Since the establishment of this technique in our theatre no patient whose VEPs during surgery have been considered acceptable has suffered any significant impairment of vision after surgery, a false negative rate of nil. In practice the use of monitoring in our unit has led to a slight increase in the duration of surgery and some changes in surgical technique as it has become apparent which actions result in impairment of the VEP. This seems to us to represent an acceptable degree of interference with surgery.

1 Wright JE, Arden G, Jones BR. Continuous monitoring of the visually evoked response during intra-orbital surgery. Trans Ophthalmol Soc UK 1973;93:311-4.

2 Feinsod M, Selhorst JB, Hoyt WF, Wilson CB. Monitoring optic nerve function during craniotomy. $J$ Neurosurg optic nerve funct
3 Wilson WB, Kirsch WM, Neville H, Stears J, Feinsod $M$ Lehman RAW. Monitoring of visual function during parasellar surgery. Surg Neurol 1976;5:323-9.

4 Albright AL, Sclabassi RJ. Cavitron ultrasonic aspirator and visual evoked potential monitoring for chiasmal gliomas in children. J Neurosurg 1985;63:138-40.

5 Allen A, Starr A, Nudleman K. Assessment of sensory function in the operating room utilizing cerebral evoked function in the operating room utilizing cerebral evoked
potentials: a study of fifty-six surgically anaesthetised potentials: a study of fifty-six surgically

6 Raudzens PA. Intraoperative monitoring of evoked potentials. Ann NY Acad Sci 1982;388:308-26.

$7 \mathrm{Hahn}$ JH, Latchaw JP. Evoked potentials in the operating room. Clin Neurosurg 1983;31:389-403.

8 Cedzich C, Schramm J, Fahlbusch R. Are flash evoked potentials useful for intraoperative monitoring of visua pathway function. Neurosurg 1987;21:709-15.

9 Cedzich C, Schramm J, Mengedoht CF, Fahlbusch R. Factors that limit the use of flash visual evoked potentials for surgical monitoring. Electroenceph Clin Neurophysiol 1988;71:142-5.

10 Koshino K, Kuroda R, Mogami H, Takimoto H. Flashing diode evoked responses for detecting optic nerve function diode evoked responses for detecting optic nerve fu
during surgery. Med J Osaka Univ 1978;29:39-47.

11 Costa E Silva I, Wang A, Symon L. The application of flash visual evoked potentials during operations on the anterior visual evoked potentials during operations
visual pathway. Neurol Res 1985;7:11-6.

12 Symon L, Moma F, Schwerdtfeger K, et al. Evoked potential monitoring in neurosurgical practice. Adv Tech Stand Neurosurg 1986;14:25-70.

13 Harding GFA, Smith VH, Yorke HC. A contact lens photostimulator for surgical monitoring. Electroenceph Clin Neurophysiol 1987;66:322-6.

14 Harding GFA, Smith VH, Yorke HC. Visual evoked potential monitoring of orbital surgery using a contact lens stimulator. In: Barber C, Blum T eds. Evoked Potenticils III. Boston: Butterworth, 1988:240-4.

15 Clark DL, Rosner BS. Neurophysiologic effects of general anesthetics Anesthesiology 1973;38:564-82. 